\title{
Heme Oxygenase-1 Does Not Mediate the Effects of Extracellular Acidosis on Vascular Smooth Muscle Cell Proliferation, Migration, and Susceptibility to Apoptosis
}

\author{
Lineke Brenninkmeijer Constantin Kuehl Adriana Miele Geldart Elena Arons \\ Helen Christou \\ Division of Newborn Medicine, Brigham and Women's and Children's Hospitals and Harvard Medical School, \\ Boston, Mass., USA
}

\section{Key Words}

Acidosis $\cdot$ Vascular homeostasis $\cdot$ Heme oxigenase-1

\begin{abstract}
Background: Unbalanced vascular smooth muscle cell (VSMC) proliferation, migration, and apoptosis contribute to vascular disorders such as atherosclerosis, restenosis, and pulmonary hypertension. The effect of extracellular acidosis (EA) on VSMC homeostasis is incompletely understood but we previously reported that EA increases heme oxygenase-1 (HO-1) expression in VSMCs. Since HO-1 regulates VSMC proliferation and apoptosis we sought to define the role of $\mathrm{HO}-1$ in VSMC responses to EA. Methods: Mouse aortic smooth muscle cells (MASMCs) were isolated from wild-type and HO1-null mice. Cell proliferation and migration assays were done in a physiologic $\mathrm{pH}$ (7.4) or EA (pH 6.8). VSMC apoptosis in response to hydrogen peroxide was assessed by JC-1 staining, caspase-3 cleavage, annexin V, and Hoechst staining. Results: Wild-type MASMCs showed decreased proliferation and migration at $\mathrm{pH} 6.8$ compared to $\mathrm{pH}$ 7.4. This observation was also true in HO-1-null MASMCs. Although wild-type and HO-1-null cells showed differences in the mode and kinetics of cell death, both genotypes exhibited increased susceptibility to hydrogen peroxide-induced apoptosis at pH 6.8 compared to 7.4. Conclusions: EA inhibits
\end{abstract}

VSMC proliferation and migration and increases susceptibility to oxidant-induced apoptosis. These effects of acidosis on VSMC homeostasis are independent of $\mathrm{HO}-1$.

Copyright $\odot 2011$ S. Karger AG, Basel

\section{Introduction}

Fully mature and differentiated vascular smooth muscle cells (VSMCs) retain remarkable plasticity which is essential for vascular maintenance and adaptation. However, phenotypic modulation of VSMCs is also important in the pathobiology of vascular obstructive disorders such as atherosclerosis, restenosis, and pulmonary hypertension. Differentiated VSMCs have a predominantly quiescent phenotype and express a unique repertoire of contractile proteins, ion channels, and signaling molecules. In contrast to this 'contractile' phenotype, dedifferentiated VSMCs are more proliferative and migratory, synthesize extracellular matrix, and are more resistant to apoptosis. This latter 'synthetic' phenotype is thought to contribute to the excessive VSMC proliferation and $\mathrm{mi}$ gration and decreased apoptosis seen in vascular neointimal lesions. Inhibition of this process through antiproliferative and/or proapoptotic approaches is a promising therapeutic strategy and the subject of intense investiga-

Dr. Helen Christou

Division of Newborn Medicine, Brigham and Women's Hospital

75 Francis Street, Thorn 1019

Boston, MA 02115 (USA)

Tel. +1 617525 8129, Fax +1 617582 6026, E-Mail hchristou@ partners.org 
tion. Although several pharmacologic approaches and drug-coated stents have been used with variable success in both the experimental and clinical settings, primary atherosclerosis or restenosis continues to be the leading cause of death in the Western world. In addition, no single intervention or pharmacologic therapy has successfully targeted the multiple contributors to the pathologic neointima formation (i.e. increased proliferation and $\mathrm{mi}$ gration and resistance to apoptosis).

Extracellular acidosis (EA) is a physiologically relevant cellular stressor that is increasingly recognized as a potent modulator of cardiovascular homeostasis, but the molecular mechanisms underlying vascular cell responses to acidosis are incompletely understood. Previous studies have mainly examined endothelial cell responses to acidosis [1-10], while the responses of VSMCs to acidosis have not been adequately studied. We previously reported that EA induces the expression of heme oxygenase-1 (HO-1) in primary VSMCs derived from the systemic and the pulmonary rat circulation [11] and that rat VSMC proliferation and migration is inhibited in the setting of EA [12]. The underlying mechanisms mediating EA-induced inhibition of proliferation and migration are unknown. We hypothesized that EA inhibits VSMC proliferation and migration and increases VSMC susceptibility to apoptosis via induction of HO-1. The present study was designed to define the effect of EA on VSMC proliferation, migration, and susceptibility to apoptosis and to define the role of HO-1 as a possible mediator of these responses. Although HO-1 and its enzymatic products are known to play an important role in vascular homeostasis through several mechanisms including the regulation of VSMC proliferation [13-15] and apoptosis $[16,17]$, our study demonstrates that the inhibition of VSMC proliferation and migration by EA is independent of HO-1. In addition, although HO-1-null and wild-type mouse aortic smooth muscle cells (MASMCs) exhibit differential susceptibility to apoptosis, both genotypes demonstrated an increased susceptibility to cell death in the setting of EA. Taken together, our data support that HO-1 is not required for EA-induced changes in VSMC homeostasis.

\section{Methods}

\section{Cell Culture and Exposure to EA}

Primary MASMCs were isolated from wild-type (Wt or $+/+$ ) mice and HO-1 knock-out (HO-1 null or -/-) mice, and their state of differentiation was characterized by morphology, alpha smooth muscle actin, and calponin staining $[18,19]$. These primary
MASMCs were grown in Dulbecco's modified Eagle's medium (DMEM) supplemented with $10 \%$ fetal calf serum (FCS) and 2 mM glutamine and passaged every 3-4 days (used between passages $4-10$ ). When they reached approximately $80 \%$ confluence, cells were subjected to $48 \mathrm{~h}$ of serum deprivation $(0.5 \%$ FCS $)$ prior to exposure to media of different $\mathrm{pH}$ values (7.4 or 6.8). To induce nonhypercapnic acidosis we used bicarbonate-free DMEM/ F12 (1:1)/0.5\% FCS media, pH-adjusted to the desired value with $100 \mathrm{mM}$ Hepes buffer, and the cells were incubated in $\mathrm{CO}_{2}$-free $37^{\circ} \mathrm{C}$ incubator for the desired time period as we previously reported $[11,12]$.

\section{Northern Analysis}

Northern analyses were performed using standard methods [11]. We used a cDNA probe specific for HO-1 [20] for Northern analysis. GAPDH mRNA levels were used for normalization, and quantification of signals was done using NIH image software.

\section{Assessment of Proliferation}

After exposure to the experimental conditions, cell proliferation was assessed by cell number and DNA synthesis was measured by 5 -bromo-2'-deoxyuridine (BrdU) incorporation as we previously reported [12]. Quadruplicate cultures of primary MASMCs were plated at equal numbers and at $80 \%$ confluence, and they were serum deprived $(0.5 \%$ FBS $)$ for $48 \mathrm{~h}$. They were then stimulated to grow in serum (20\%) and/or platelet-derived growth factor-BB (PDGF-BB; $25 \mathrm{ng} / \mathrm{ml}$ ) in media of $\mathrm{pH} 6.8$ or 7.4 . Viable cells were counted at serial time points from parallel plates using the Trypan blue exclusion method, and the number of dead cells per condition was noted. For the assessment of DNA synthesis, MASMCs were plated at equal numbers in a 96-well plate and, after $48 \mathrm{~h}$ of serum deprivation ( $0.5 \% \mathrm{FBS})$, they were stimulated to grow in serum or PDGF-BB in media of $\mathrm{pH} 6.8$ or 7.4 overnight. BrdU (10 mol/l) was added for the last $3 \mathrm{~h}$ of the 24-hour incubation, and a chemiluminescence immunoassay (Roche) was used to compare DNA synthesis among the experimental conditions.

\section{Migration Assays}

Equal numbers of MASMCs $\left(5 \times 10^{5}\right)$ were plated on the top chamber of Transwell plates (pore size $8.0 \mu \mathrm{m}$; Transwell-Costar Corporation, Cambridge, Mass., USA) and $50 \mathrm{ng} / \mathrm{ml}$ of PDGF-BB was added in the lower chamber. After exposure to the experimental conditions, the top chamber was scraped and live cells were quantified in the lower chamber by an acid phosphatase enzymatic assay as previously described [12, 21, 22].

\section{Apoptosis Assays}

The susceptibility of MASMCs to oxidant-induced apoptosis was assessed after exposure to hydrogen peroxide $\left(\mathrm{H}_{2} \mathrm{O}_{2}\right)$ at 100 or $300 \mu \mathrm{M}$. We used 4 methods to assess apoptosis in a quantitative way: (1) Mitochondrial membrane potential $(\Delta \Psi \mathrm{m})$ was assessed by JC-1 staining and spectrophotometric analysis. This assay measures, in a quantitative way, the loss of mitochondrial transmembrane potential which is believed to be an early event in the apoptotic process. It utilizes the property of the lipophilic fluorescent dye JC-1 to enter healthy mitochondria and stain them red but stays in its monomeric green form in the cytoplasm if the mitochondria are depolarized (as occurs during the apoptotic process). Cells were serum deprived (0.5\% FBS in DMEM) for $48 \mathrm{~h}$ and subjected to exposure to acidosis ( $\mathrm{pH} 6.8$ ) or a phys- 
iologic $\mathrm{pH}$ (7.4) for $8 \mathrm{~h}$, followed by the addition of $100 \mu \mathrm{M} \mathrm{H}_{2} \mathrm{O}_{2}$ for $24 \mathrm{~h}$. JC-1 staining was done according to the manufacturer's instructions (Mitochondrial Membrane Potential Detection Kit; Stratagene), and determination of fluorescence was done in a black 96-well plate using a fluorescence plate reader. Both red $(585 / 590 \mathrm{~nm})$ and green $(510 / 527 \mathrm{~nm})$ fluorescences were measured, and the red-to-green fluorescence ratio was determined. This ratio decreases as $\Delta \Psi \mathrm{m}$ decreases in cells that undergo apoptosis. (2) Caspase-3 cleavage was assessed by Western analysis. After exposure to the experimental conditions, the cells were lysed in lysis buffer (cell signaling), and a standard SDS-PAGE protocol was followed. Caspase-3 antibody (cell signaling) at a 1:1,000 dilution was used as the primary antibody and mouse anti-rabbit antibody at a 1:2,000 dilution as the secondary antibody. (3) Annexin $\mathrm{V}$ binding was assessed by annexin $\mathrm{V}$ and propidium iodide (PI) staining (Annexin V Apoptosis Detection Kit; BioVision) and flow cytometry. After exposure to the experimental conditions, cells were harvested by trypsinization and gentle cell scraping and collected together with the cell culture supernatant. Cells were labeled with PI and FITC-conjugated annexin V, and fluorescence signal intensity was assessed using a FACS-Canto-II flow cytometer (Beckton Dickinson). Data analysis was performed with FlowJo software (Stanford, version 8.8.4). Ten thousand events were acquired and analyzed for each experimental condition. (4) Apoptotic nuclear condensation was assessed by Hoechst 33258 staining. Cells were plated on coverslips at 40,000 cells/well in a 6-well plate, serum deprived with $0.5 \% \mathrm{D}$-MEM for $48 \mathrm{~h}$, and subsequently exposed for 24 or $48 \mathrm{~h}$ to acidosis ( $\mathrm{pH} 6.8$ ) with or without simultaneous exposure to 100 or $300 \mu \mathrm{M} \mathrm{H}_{2} \mathrm{O}_{2}$. After $48 \mathrm{~h}$ of exposure, cells were fixed with $3 \%$ paraformaldehyde, stained with Hoechst $33258(1 \mu \mathrm{g} / \mathrm{ml})$, and visualized by fluorescent microscopy. Counting was done by choosing 5 random fields at a $20 \times$ magnification and counting the percentage of condensed (apoptotic) nuclei.

Statistical Analysis

Statistical analysis of cell number, BrdU incorporation, cell migration, and JC-1 staining was done with 1-way ANOVA (Kruskal-Wallis, GraphPad Prism, version 5). We used 2-way ANOVA (GraphPad Prism, version 5) to analyze annexin V staining and Hoechst staining. $\mathrm{p}<0.05$ was considered statistically significant.

\section{Results}

\section{Extracellular Acidosis Inhibits VSMC Proliferation} Independently of HO-1 Induction

To elucidate the functional implications of HO-1 upregulation by EA we exposed wild-type and HO-1-null MASMCs to 2 proliferative stimuli (serum and PDGF$\mathrm{BB}$ ) in the setting of EA, and we assessed cell number and DNA synthesis. As shown in figure 1a, 18-hour exposure to an extracellular $\mathrm{pH}$ of 6.8 significantly induced $\mathrm{HO}-1$ mRNA levels in MASMCs derived from wild-type mice, while there was no HO-1 message detected in the MASMCs derived from $\mathrm{HO}-1-$ null mice. As seen in fig- ure $1 \mathrm{~b}$, MASMC proliferation in response to serum or PDGF-BB stimulation was inhibited in the setting of EA in both wild-type and HO-1-null cells. The number of dead cells under the same experimental conditions was less than $10 \%$ and was not altered by exposure to EA. As shown in figure 1c, there was significantly lower DNA synthesis as assessed by $\mathrm{BrDU}$ incorporation in response to PDGF-BB in the setting of EA compared to a physiologic $\mathrm{pH}$ in both wild-type and HO-1-null cells.

\section{Extracellular Acidosis Inhibits VSMC Migration \\ Independently of HO-1 Induction}

In order to define the role of HO-1 in mediating the effects of EA on VSMC migration, we examined the responses of wild-type and HO-1-null MASMCs to the chemotactic stimulus PDGF-BB in the setting of EA. As shown in figure 2, MASMC migration in response to PDGF-BB was inhibited by EA in both wild-type and HO-1-null cells, thus supporting that the inhibition of MASMC migration by EA is independent of HO-1.

\section{Extracellular Acidosis Increases Early Apoptotic \\ Changes in Response to $\mathrm{H}_{2} \mathrm{O}_{2}$ Independently of HO-1}

In order to examine the effect of EA on VSMC apoptotic responses to a known proapoptotic stimulus, we exposed wild-type and $\mathrm{HO}-1$-null MASMCs to $\mathrm{H}_{2} \mathrm{O}_{2}$ which is known to induce apoptosis via the intrinsic (mitochondrial) pathway. We then examined early apoptotic events, specifically mitochondrial membrane depolarization and caspase-3 cleavage. As shown in figure 3, in both wild-type and HO-1-null cells, exposure to EA led to a significant reduction in mitochondrial membrane potential in the presence of hydrogen peroxide compared to cells kept at a physiologic $\mathrm{pH}$. As shown in figure $4 \mathrm{~b}$, exposure to EA in the presence of $100 \mu \mathrm{M} \mathrm{H}_{2} \mathrm{O}_{2}$ led to caspase- 3 cleavage, whereas the same exposure to $\mathrm{H}_{2} \mathrm{O}_{2}$ (in terms of dose and duration) at $\mathrm{pH} 7.4$ was not associated with the presence of cleaved caspase-3. This was observed in both wild-type and HO-1-null cells. A higher dose of $\mathrm{H}_{2} \mathrm{O}_{2}(300 \mu \mathrm{M})$ or a longer duration of exposure $(48 \mathrm{~h})$ resulted in caspase-3 cleavage in both experimental conditions ( $\mathrm{pH} 7.4$ and 6.8) and in both cell genotypes.

\section{EA Increased Susceptibility to $\mathrm{H}_{2} \mathrm{O}_{2}$-Induced Cell Death Independently of HO-1}

Late apoptotic events include phosphatidyl exposure, nuclear condensation, and fragmentation. These events are followed by cell death that can be examined by PI uptake. We assessed the effect of EA on these apoptotic events and cell death in response to $\mathrm{H}_{2} \mathrm{O}_{2}$ using annexin 


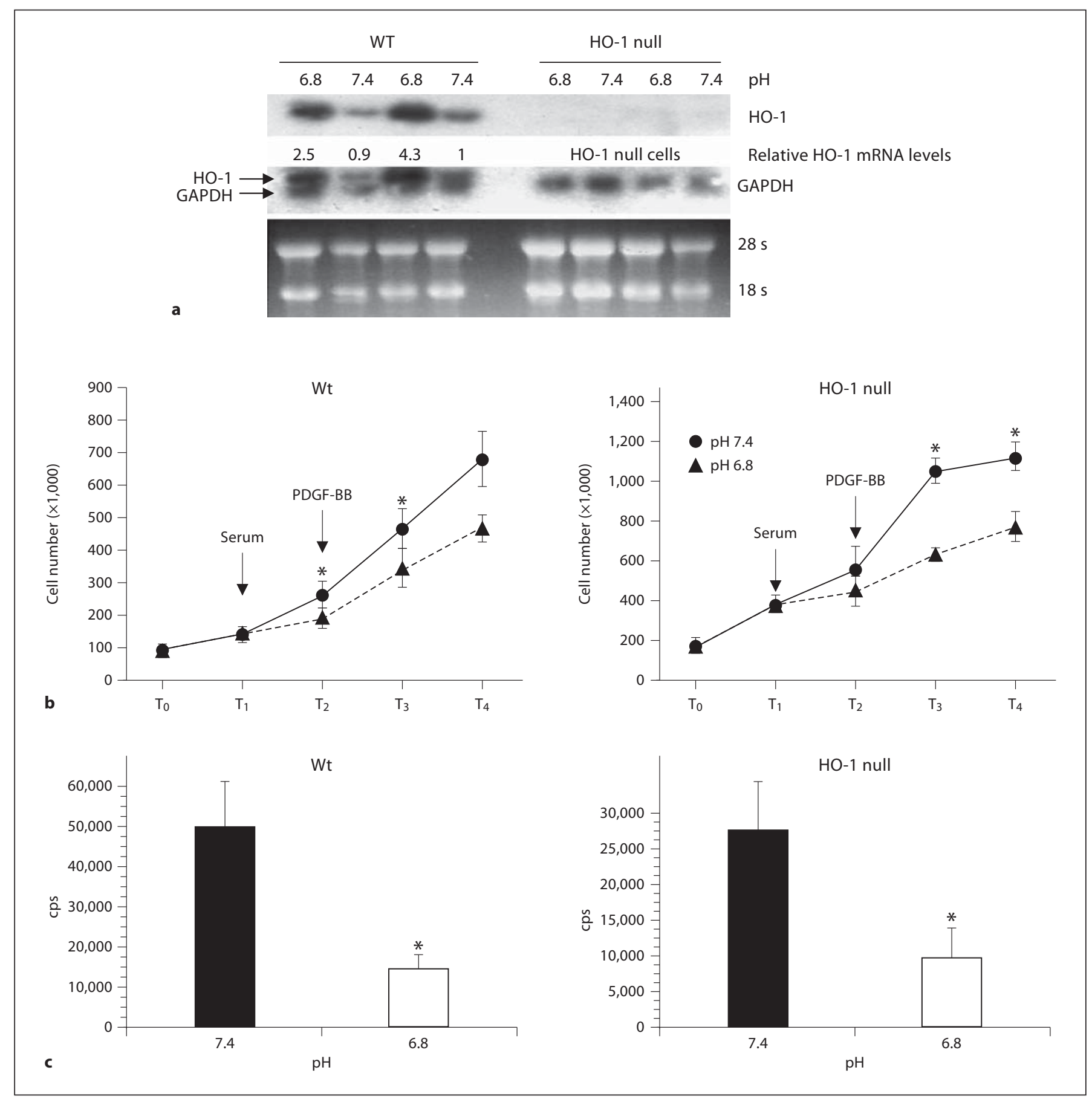

Fig. 1. Effect of extracellular acidosis on HO-1 mRNA regulation and proliferative responses of wild-type and HO-1-null VSMCs. a Representative Northern blot depicting levels of HO-1 and GAPDH mRNA after exposure to EA ( $\mathrm{pH}$ 6.8) or media of a physiologic $\mathrm{pH}$ (7.4) for $18 \mathrm{~h}$. Relative HO-1 mRNA levels are normalized to GAPDH. The ethidium bromide photograph of the membrane demonstrates equal loading (28 and $18 \mathrm{~s}$ are the ribosomal RNA subunits). $\mathbf{b}$ Cell number in response to serum and PDGFBB. Quadruplicate cultures of primary MASMCs were plated at equal numbers and grown to $80 \%$ confluence $\left(\mathrm{T}_{0}\right)$. They were se-

rum deprived ( $0.5 \% \mathrm{FBS})$ for $48 \mathrm{~h}\left(\mathrm{~T}_{1}\right)$ and then stimulated to proliferate in serum in media of $\mathrm{pH} 6.8$ or 7.4 overnight $\left(\mathrm{T}_{2}\right)$. A second growth stimulus (PDGF-BB $25 \mathrm{ng} / \mathrm{ml}$ ) was then added and cell counts were assessed $18 \mathrm{~h}\left(\mathrm{~T}_{3}\right)$ and $48 \mathrm{~h}\left(\mathrm{~T}_{4}\right)$ after the addition of PDGF-BB. The mean and SEM values are shown. ${ }^{*} \mathrm{p}<0.05$ (comparisons were made between the 2 experimental conditions). c BrdU incorporation in primary MASMCs in response to PDGF$\mathrm{BB}$ in the setting of EA ( $\mathrm{pH}$ 6.8) or a physiologic $\mathrm{pH}$ (7.4). The mean and SEM counts per second (cps) of 5 independent experiments are shown. ${ }^{*} \mathrm{p}<0.0001$. Wt $=$ Wild type. 


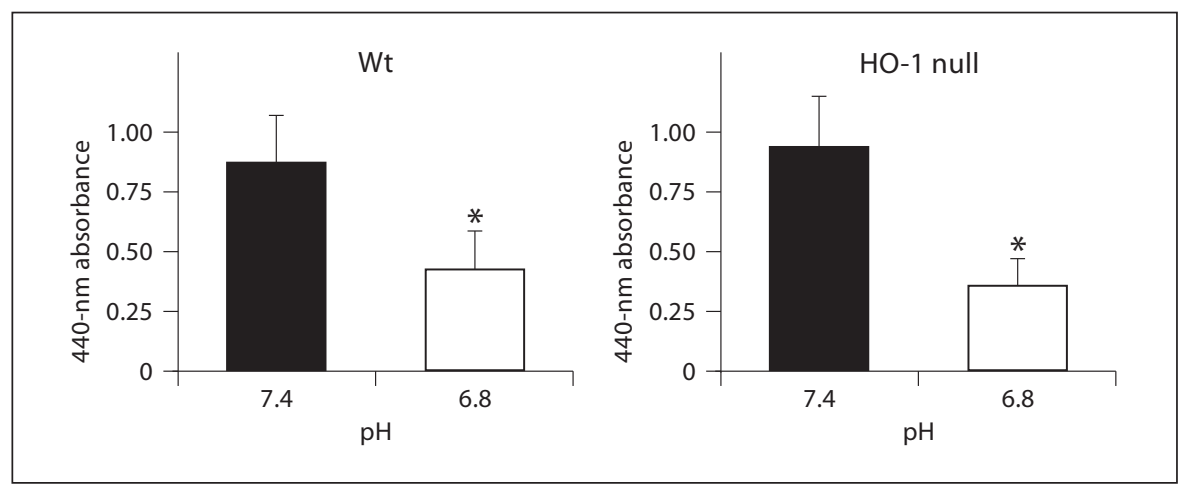

Fig. 2. Migratory responses of wild-type and HO-1-null MASMCs to PDGF-BB in the setting of EA. Cell migration assays were performed using Transwell plates. Subconfluent cells of primary MASMCs were trypsinized, neutralized, and resuspended in DMEM, with $0.1 \%$ BSA. The same number of cells $\left(5 \times 10^{5}\right)$ were added to the top of each migration chamber in the setting of EA ( $\mathrm{pH} 6.8)$ or a physiologic $\mathrm{pH}(7.4)$ and were allowed to migrate to the underside of the chamber overnight in the presence of $50 \mathrm{ng} /$ $\mathrm{ml}$ PDGF-BB in the lower chamber. The upper side of the filter was then scraped off and the filter was removed. VSMCs that had migrated to the lower side of the filter were quantified with an acid phosphatase enzymatic assay. The mean optical density at $440 \mathrm{~nm}$ $\left(\mathrm{OD}_{440 \mathrm{~nm}}\right)$ and SEM from 5 independent experiments are shown. ${ }^{*} \mathrm{p}<0.05$.

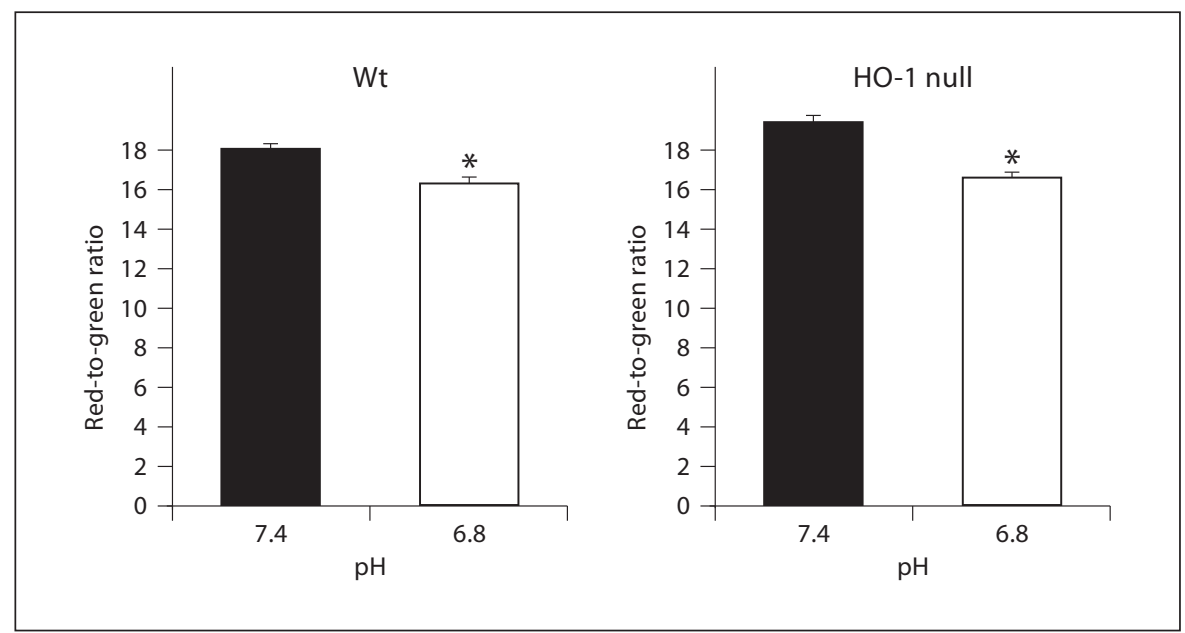

Fig. 3. Mitochondrial membrane potential as measured by JC-1 staining. Primary wild-type and HO-1 MASMCs were serum deprived at $80 \%$ confluence ( $0.5 \%$ FBS in DMEM) for $48 \mathrm{~h}$ and subjected to exposure to acidosis ( $\mathrm{pH}$ 6.8) or a physiologic $\mathrm{pH}$ (7.4) for $8 \mathrm{~h}$, followed by the addition of $100 \mu \mathrm{M} \mathrm{H}_{2} \mathrm{O}_{2}$ for $24 \mathrm{~h}$. After JC- 1 staining, the determination of fluorescence was done in a black 96-well plate using a fluorescence plate reader. Both red (585/590 $\mathrm{nm})$ and green $(510 / 527 \mathrm{~nm})$ fluorescences were measured and the ratio of red-to-green fluorescence was determined. The mean and SEM of the red-to-green ratio of 5 independent experiments is shown. ${ }^{*} \mathrm{p}<0.05$.
V/PI staining and flow cytometry and Hoechst staining. As shown in figure 5 , exposure to $\mathrm{H}_{2} \mathrm{O}_{2}$ decreases the percentage of viable cells (annexin $\mathrm{V}$ negative and PI negative) in both wild-type (fig. 5b) and HO-1-null cells (fig. 5c), and this reduction is significantly increased by concomitant exposure to EA. The percentage of apoptotic cells (annexin V positive and PI negative) is sig- nificantly increased with exposure to $\mathrm{H}_{2} \mathrm{O}_{2}$ in both genotypes, but the importance of EA in accentuating this increase reached significance only in the $\mathrm{HO}-1$-null cells (fig. 5e). A similar trend was observed in wild-type cells. As shown in figures 6 and 7, exposure to EA led to a timedependent increase in the percentage of condensed nuclei in the presence of $100 \mu \mathrm{M} \mathrm{H}_{2} \mathrm{O}_{2}$ for 24 or $48 \mathrm{~h}$ as assessed 


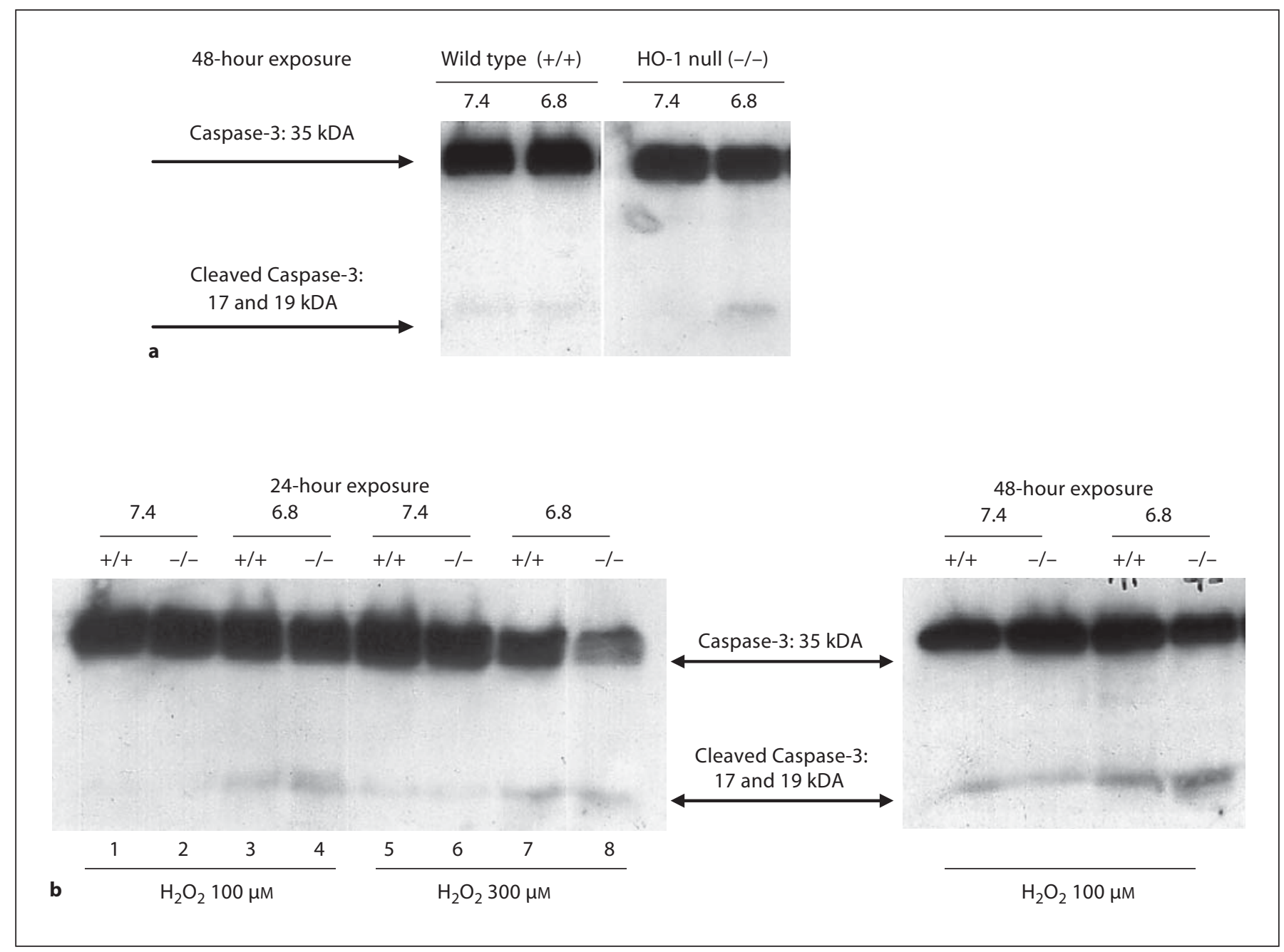

Fig. 4. Western analysis of caspase-3 in wild-type and HO-1-null MASMCs in response to EA and $\mathrm{H}_{2} \mathrm{O}_{2}$. a Wild-type and $\mathrm{HO}-1$ null MASMCs were subjected to $48 \mathrm{~h}$ of serum deprivation followed by exposure to acidic media ( $\mathrm{pH}$ 6.8) or media of $\mathrm{pH} 7.4$ for $48 \mathrm{~h}$. b Cells were subjected to $48 \mathrm{~h}$ of serum deprivation followed by exposure to acidic media ( $\mathrm{pH}$ 6.8) or media of $\mathrm{pH} 7.4$ in the

by Hoechst staining. This was observed in both wild-type and HO-1-null cells; however, these differences did not reach statistical significance (fig. 8). At a higher $\mathrm{H}_{2} \mathrm{O}_{2}$ concentration $(300 \mu \mathrm{M})$ there were very few cells left after $48 \mathrm{~h}$, especially at $\mathrm{pH} 6.8$, due to cell death and detachment, and the majority of the cells left at $\mathrm{pH} 7.4$ were apoptotic (data not shown).

\section{Differential Susceptibility of Wild-Type and}

HO-1-Null Cells to EA and $\mathrm{H}_{2} \mathrm{O}_{2}$-Induced Apoptosis

The effect of EA alone on VSMC apoptosis has not been previously studied. In wild-type MASMCs, al- presence of 100 or $300 \mu \mathrm{m} \mathrm{H}_{2} \mathrm{O}_{2}$ for 24 or $48 \mathrm{~h}$. Wild-type cells are designated $+/+$ and $\mathrm{HO}-1$-null cells are designated $-/-$. The cleaved caspase- 3 band at 17 and $19 \mathrm{KDa}$ and the intact caspase- 3 band at $35 \mathrm{kDa}$ are indicated by arrows. Each experiment was done at least 3 times.

though we found a decreased mitochondrial potential after exposure to acidosis, we found no caspase-3 cleavage for up to $48 \mathrm{~h}$ of exposure to acidosis (fig. $4 \mathrm{a}$ ) as well as no significant changes in the percentage of annexin V-positive cells (fig. 5d) or condensed nuclei (fig. 8a) or the percentage of viable cells (fig. 5b). We therefore deduce that EA alone does not induce apoptosis in wild-type MASMCs and that the observed inhibition in VSMC proliferation and migration is due to a true inhibitory effect of EA on proliferative and migratory responses.

In HO-1-null cells we found an increased susceptibility to EA-induced early apoptotic changes as evidenced 


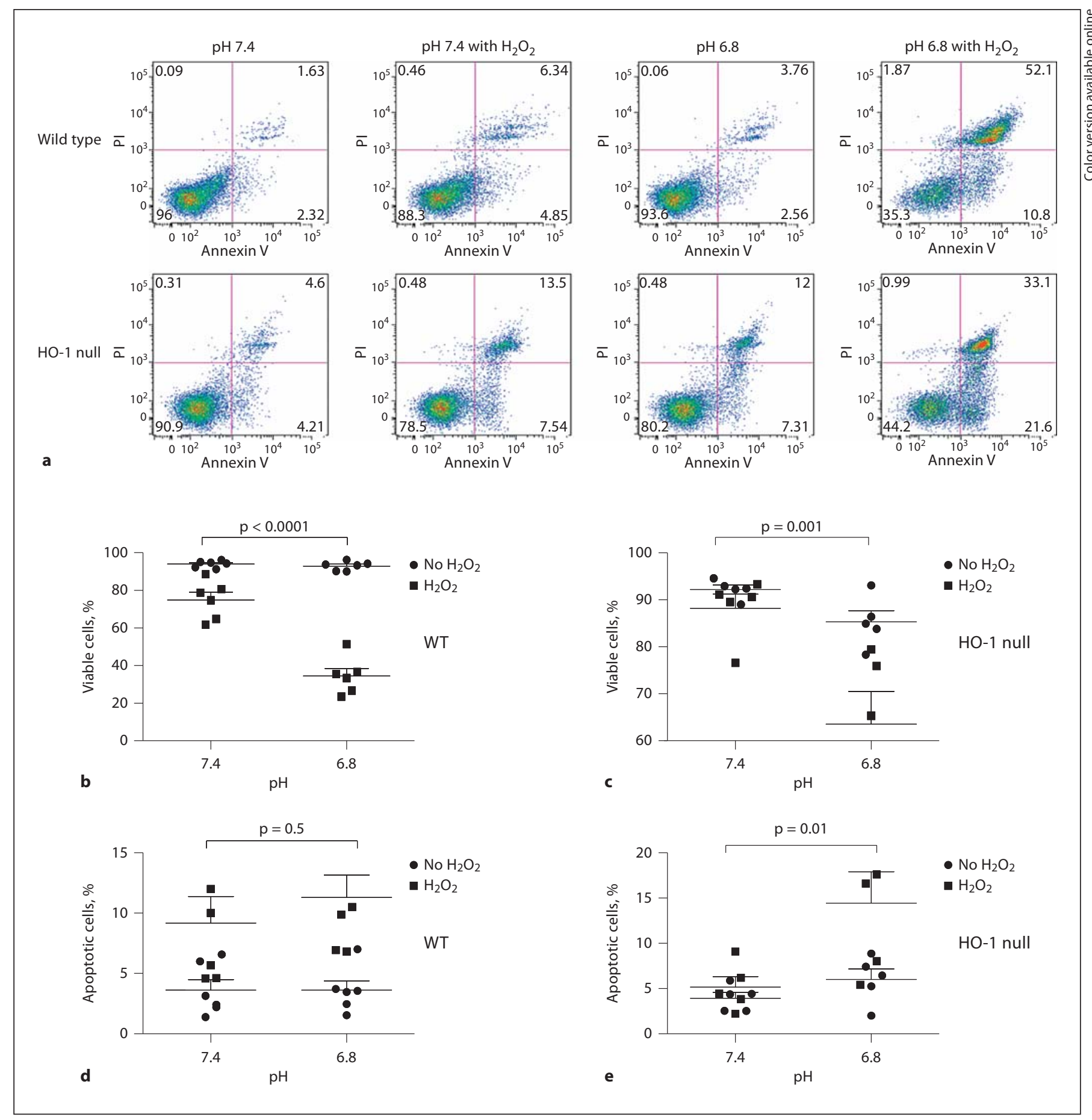

Fig. 5. Annexin V staining in wild-type and HO-1-null MASMCs in response to EA and $\mathrm{H}_{2} \mathrm{O}_{2}$. Representative flow cytometry data. Cells were subjected to serum deprivation for $48 \mathrm{~h}$ followed by exposure to acidic media ( $\mathrm{pH}$ 6.8) or media of $\mathrm{pH} 7.4$ in the presence of $300 \mu \mathrm{M} \mathrm{H}_{2} \mathrm{O}_{2}$ for $24 \mathrm{~h}$. Cells were labeled with PI and FITC-conjugated annexin $\mathrm{V}$ and fluorescence signal intensity was assessed using a FACS-Canto-II flow cytometer (Beckton Dickinson). Data analysis was performed with FlowJo software (Stanford, version 8.8.4). Ten thousand cells were acquired and ana- lyzed for each experimental condition. b-e Quantitative analysis of data (from 6 independent experiments). b Percentage of wildtype viable cells (annexin V negative, PI negative). c Percentage of HO-1-null viable cells (annexin V negative, PI negative). d Percentage of apoptotic wild-type cells (annexin $\mathrm{V}$ positive, PI negative). e Percentage of apoptotic HO-1-null cells (annexin V positive, PI negative). Statistical analysis was done by 2 -way ANOVA. $\mathrm{Wt}=$ Wild type. 

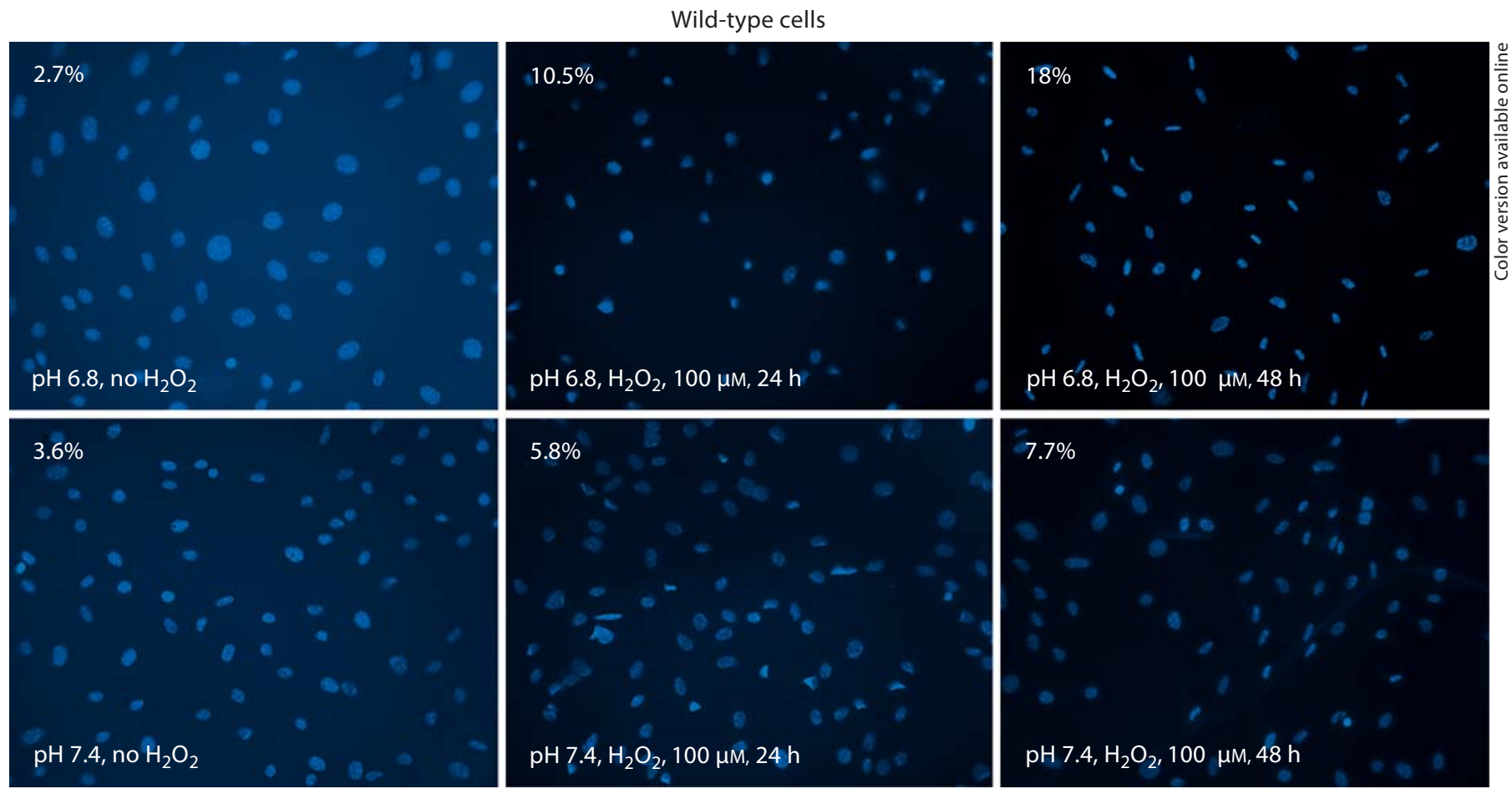

Fig. 6. Nuclear condensation as assessed by Hoechst staining in wild-type MASMCs exposed to $\mathrm{H}_{2} \mathrm{O}_{2}$ and EA. Primary MASMCs from wild-type mice were seeded on poly-D-lysine-coated coverslips and subjected to $48 \mathrm{~h}$ of serum deprivation prior to exposure to media of pH 6.8 or 7.4 in the presence or absence of $100 \mu \mathrm{M}$ $\mathrm{H}_{2} \mathrm{O}_{2}$. The duration of exposure was 24 or $48 \mathrm{~h}$ and the cells were subsequently fixed and stained with Hoechst 33258 and visualized by fluorescence microscopy. Representative fluorescent images from 3 independent experiments are shown $(20 \times$ magnification) and the percentage of condensed nuclei is indicated in each photomicrograph. by a decrease in mitochondrial potential and the presence of cleaved caspase- 3 after $48 \mathrm{~h}$ of exposure to EA (fig. $4 \mathrm{a}$ ). However, this was not accompanied by significant differences in annexin V-positive cells (fig. 5e) or the percentage of condensed nuclei (fig. 8b) or the percentage of viable cells (fig. $5 \mathrm{c}$ ). In contrast, in the presence of a known proapoptotic stimulus $\left(\mathrm{H}_{2} \mathrm{O}_{2}\right)$, we found that $\mathrm{HO}-1$-null cells were more susceptible to apoptosis than were wildtype cells at either extracellular $\mathrm{pH}$ (fig. 9a). This difference was statistically significant when cells were assessed by Hoechst staining but did not reach statistical significance when the cells were assessed by annexin V staining and flow cytometry (fig. 9b).

\section{Discussion}

We report that acidic extracellular $\mathrm{pH}$ inhibits VSMC proliferation and migration and increases VSMC susceptibility to apoptosis. In addition, using MASMCs derived from wild-type and HO-1-null mice, we demonstrate that these effects are independent of HO-1. The molecular mechanisms underlying these VSMC responses to EA may involve multiple intracellular signaling pathways that need to be further defined.

To our knowledge, this is the first study on the effect of nonhypercapnic EA on VSMC homeostasis. Previous studies on the role of acidosis in vascular homeostasis have mainly focused on endothelial cell responses and on hypercapnic acidosis. Hypercapnic acidosis decreased the expression of intercellular adhesion molecule-1 (ICAM-1) in human aortic endothelial cells but increased the neutrophil-endothelial adhesion via a neutrophil-dependent CD-18-mediated pathway [5]. D'Arcangelo et al. [23] reported that hypercapnic acidosis increased vascular endothelial growth factor (VEGF) and basic fibroblast growth factor (bFGF) expression in bovine aortic endothelial cells when the $\mathrm{pH}$ was lowered from 7.4 to 7.0. Staurosporine-induced apoptosis in human pulmonary artery endothelial cells was prevented by exposure to nor- 
HO-1-null cells
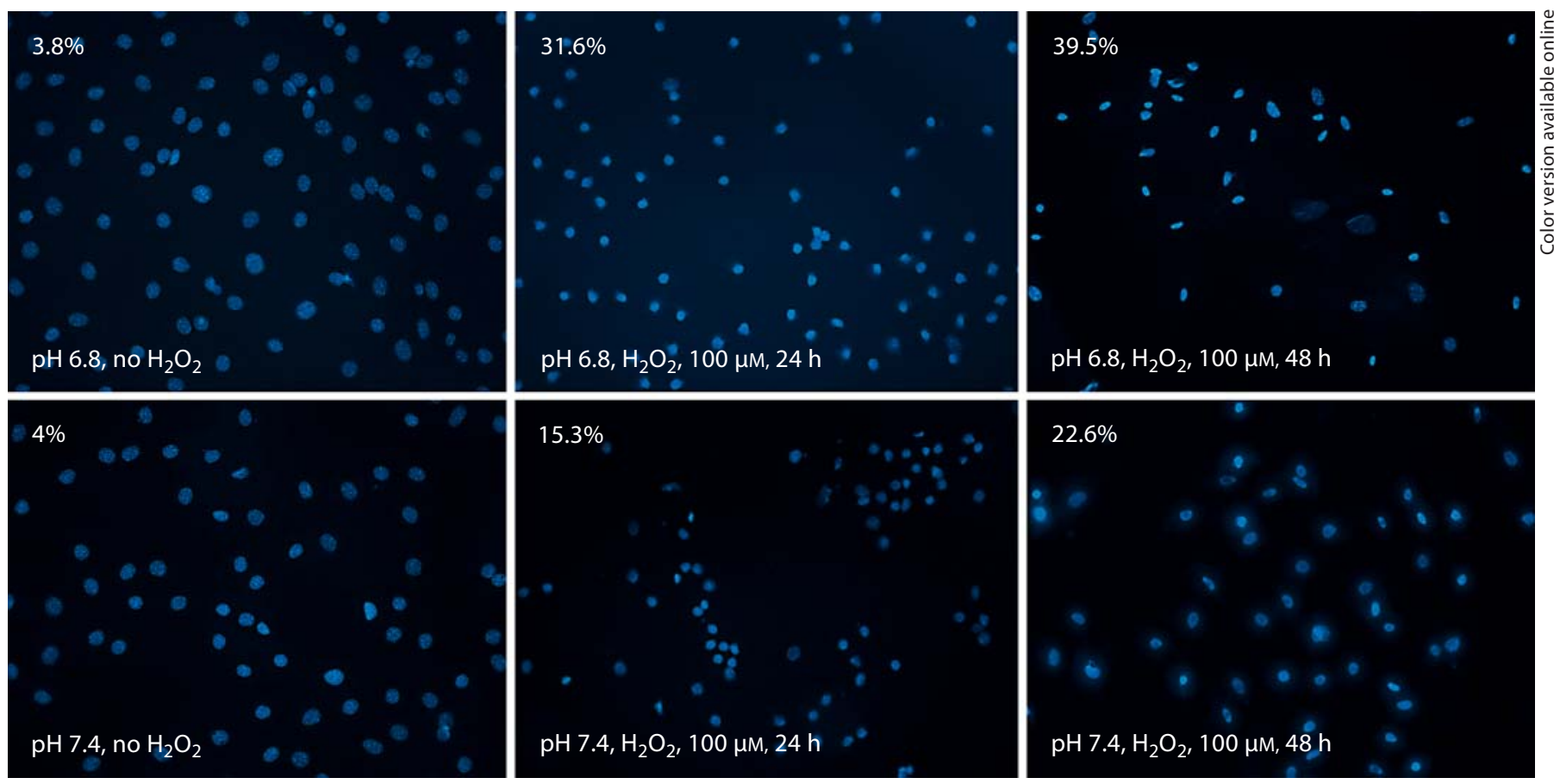

Fig. 7. Nuclear condensation as assessed by Hoechst staining in HO-1-null MASMCs exposed to $\mathrm{H}_{2} \mathrm{O}_{2}$ and EA. Primary MASMCs from $\mathrm{HO}-1$-null mice were seeded on poly-D-lysine-coated coverslips and subjected to $48 \mathrm{~h}$ of serum deprivation prior to exposure to media of $\mathrm{pH} 6.8$ or 7.4 in the presence or absence of $100 \mu \mathrm{M}$ $\mathrm{H}_{2} \mathrm{O}_{2}$. The duration of exposure was 24 or $48 \mathrm{~h}$ and the cells were

subsequently fixed and stained with Hoechst 33258 and visualized by fluorescence microscopy. Representative fluorescent images from 3 independent experiments are shown $(20 \times$ magnification) and the percentage of condensed nuclei is indicated in each photomicrograph.

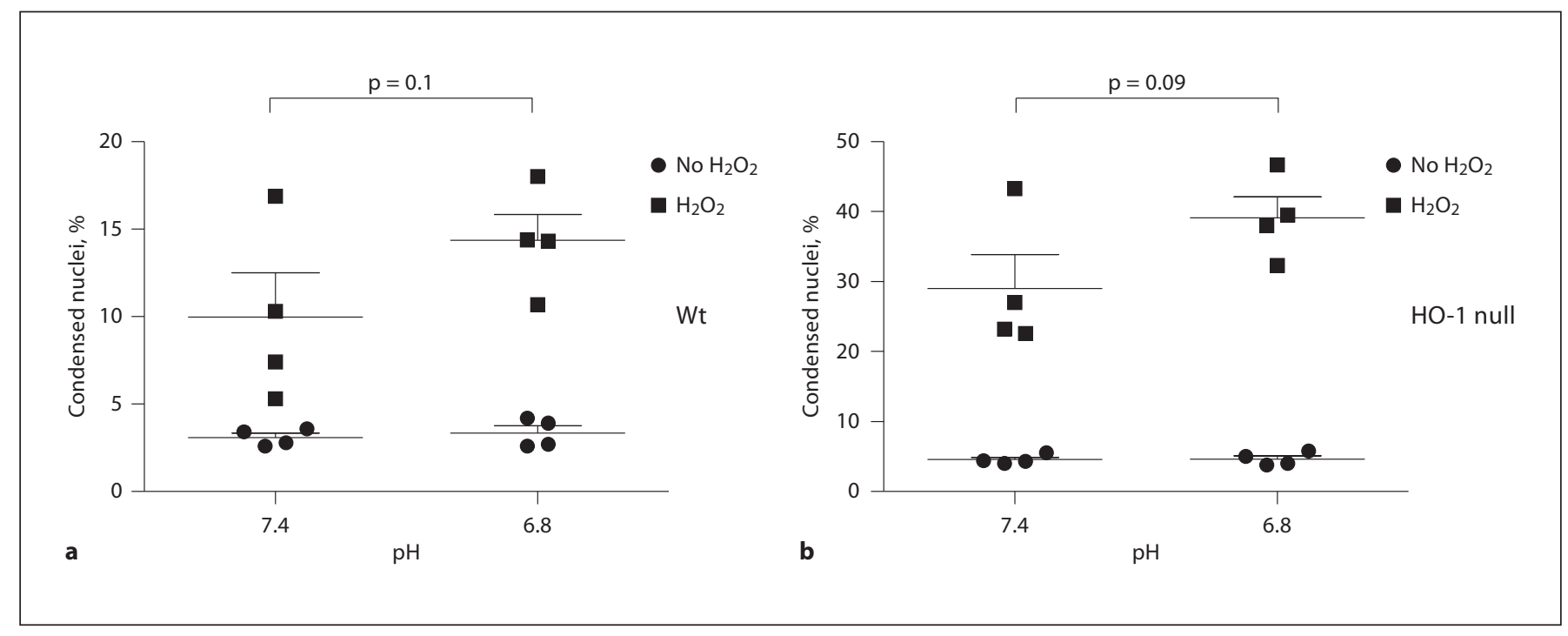

Fig. 8. Quantitative analysis of condensed nuclei as assessed by Hoechst staining in wild-type and HO-1-null MASMCs exposed to $\mathrm{H}_{2} \mathrm{O}_{2}$ and EA. Quantitative data from 4 independent experiments $\left(\mathrm{H}_{2} \mathrm{O}_{2}\right.$ dose is $\left.100 \mu \mathrm{M}\right)$ are shown and statistical analysis was done with 2-way ANOVA. Wt $=$ Wild type. 


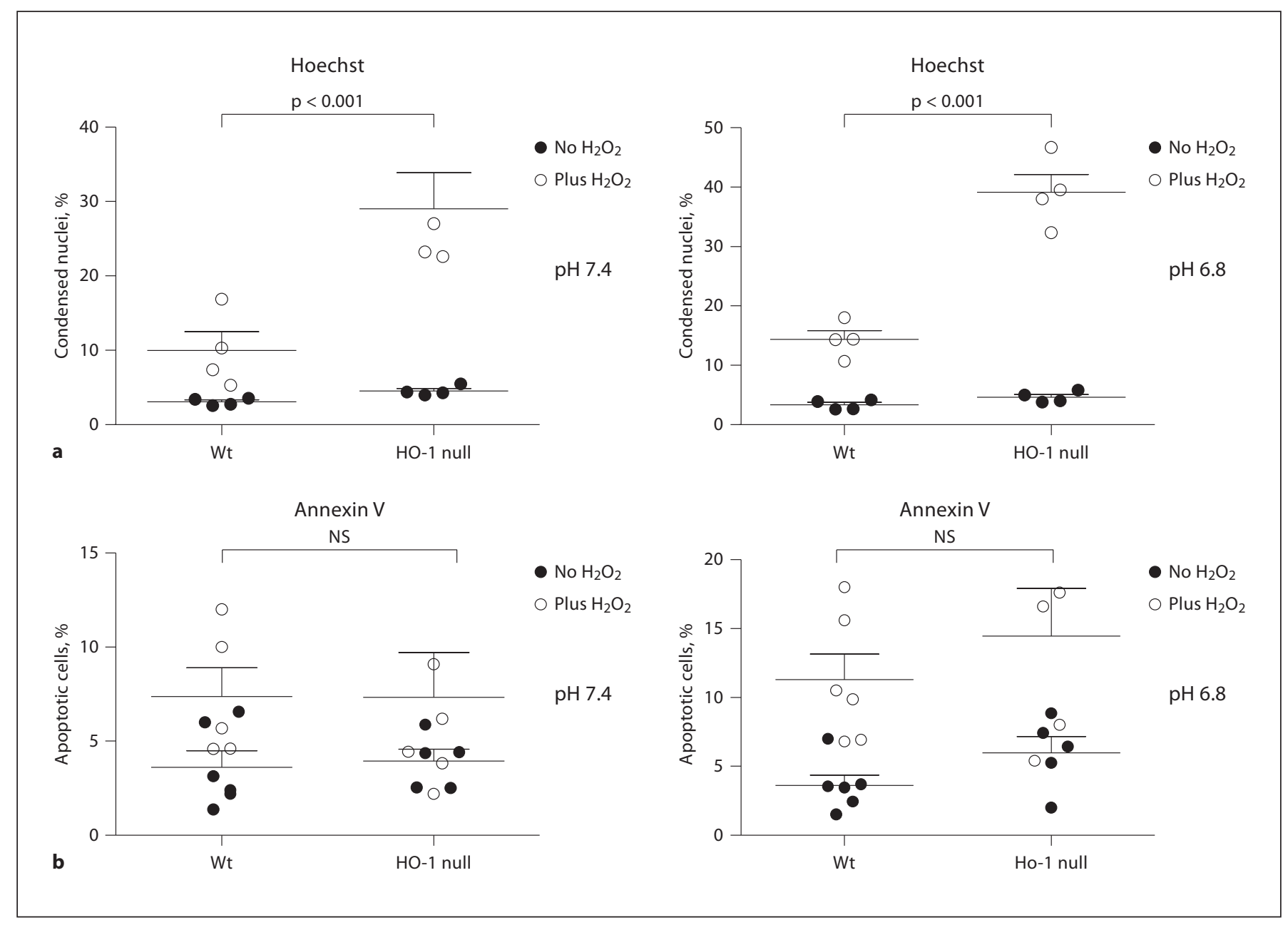

Fig. 9. Quantitative analysis of condensed nuclei as assessed by Hoechst staining (a) and percentage of apoptotic cells as assessed by annexin $\mathrm{V}$ staining and flow cytometry (b) in wild-type and HO-1-null MASMCs exposed to $\mathrm{H}_{2} \mathrm{O}_{2}$ and EA. Quantitative data from 4-6 independent experiments $\left(\mathrm{H}_{2} \mathrm{O}_{2}\right.$ dose is $\left.100 \mu \mathrm{M}\right)$ are shown and statistical analysis was done with 2-way ANOVA. NS = Nonsignificant difference; Wt = wild type.

mocapnic acidosis possibly via a $\mathrm{pH}$-induced alteration in $\mathrm{Ca}^{2+}$ signaling [6]. Agullo et al. [1] reported that acidosis further compromised cyclic GMP production in hypoxic microvascular coronary endothelial cells. The significance of these observations in terms of endothelial cell function and endothelial cell-VSMC interactions has not been elucidated and, more importantly, the in vivo implications of these endothelial cell responses to acidosis in the context of vascular disease processes remain to be determined.

Previous studies on the effect of acidosis in VSMC homeostasis have mainly focused on hypercapnic acidosis and ion channel physiology. Extracellular pH is known to interfere with ion channel activity in VSMCs, thereby al- tering contractility $[24,25]$, but this effect appears to be vascular bed-specific. Altered activity of the ATP-sensitive $\mathrm{K}^{+}$channel Kir 6.1/SUR 2B was identified as critical in the regulation of vascular tone during hypercapnic acidosis $[25,26]$. Given that potassium channels also have a regulatory role in VSMC proliferation $[27,28]$ it is plausible that acidosis-induced changes such as altered $\mathrm{K}^{+}$ channel activity may have effects on VSMC proliferation. We previously reported that $\mathrm{HO}-1$ is upregulated in systemic and pulmonary VSMC exposed to EA [11] by both transcriptional and posttranscriptional mechanisms. We also reported that the p38 MAPK pathway is involved in the regulation of HO-1 by EA [12] and that EA inhibited the proliferation and migration of rat VSMCs. Since 
HO-1 and its enzymatic products, carbon monoxide and biliverdin (converted to bilirubin), are known to exert antiproliferative and antimigratory effects in VSMCs and to modulate their susceptibility to apoptosis $[16,29,30]$, we sought to examine whether the effects of EA on VSMC homeostasis are mediated by HO-1. In this study we found that nonhypercapnic acidosis inhibited VSMC proliferation and migration in both wild-type and HO-1null cells, and we concluded that the antiproliferative and antimigratory effect of acidosis is not mediated by HO-1. Since we did not find an increased number of dead or apoptotic cells in our experimental conditions, we are confident that the observed effects of EA on proliferation and migration are due to a direct effect of acidosis on the proliferative and migratory cellular responses. On the other hand, we cannot exclude the possibility that our results in HO-1-null cells may be confounded by the upregulation of other compensatory mechanisms in these genetically modified cells. Since our current data support that the effects of acidosis on VSMC proliferation and migration are not mediated by HO-1, alternative molecular mechanisms need to be further explored.

The role of HO-1 and its enzymatic products in VSMC apoptosis is complex and likely dependent on the experimental conditions. Specifically, Liu et al. [16] reported that adenoviral-induced HO-1 overexpression or exogenous biliverdin administration induced apoptosis in rat aortic smooth muscle cells (RASMCs). In contrast, exogenously administered or endogenously produced carbon monoxide was reported to inhibit cytokine-induced apoptosis in RASMCs [17]. Similarly, Brunt et al. [31] reported that $\mathrm{HO}-1$ attenuated $\mathrm{H}_{2} \mathrm{O}_{2}$-induced apoptosis in human VSMCs. HO-1 also had proproliferative and antiapoptotic effects in microvascular endothelial cells [32] and in cancer cells [33]. Under our experimental conditions, we found that EA increased the susceptibility of wild-type and $\mathrm{HO}-1$-null cells to $\mathrm{H}_{2} \mathrm{O}_{2}$-induced apoptosis and ultimately cell death. Since the response of HO-1null cells to acidosis was similar to that of wild-type VSMCs, we concluded that the effect of acidosis on VSMC susceptibility to apoptosis is independent of HO-1. However, in direct comparisons of wild-type and HO-1-null cells we observed that, regardless of the extracellular $\mathrm{pH}$, $\mathrm{HO}-1$-null cells appear to be more sensitive to $\mathrm{H}_{2} \mathrm{O}_{2}$-induced cell death, likely by apoptosis. This suggests that $\mathrm{HO}-1$ exerts an antiapoptotic effect or has a protective effect against oxidant stress induced by $\mathrm{H}_{2} \mathrm{O}_{2}$. This finding is in agreement with prior studies as cited above and may be mediated by one of the enzymatic products of HO-1, specifically biliverdin which is a known antioxidant.
Moreover, in the absence of $\mathrm{H}_{2} \mathrm{O}_{2}, \mathrm{HO}-1$-null cells appeared to be more susceptible than wild-type cells to acidosis-induced cell death by both apoptosis and necrosis but these differences were not significant. By using multiple apoptosis assays, we examined multiple stages of the apoptotic process and found mostly consistent results. Apparent inconsistencies in our results may be related to the different aspects of the apoptotic process assessed by each method, the time-dependent nature of apoptotic changes in relation to the apoptotic stimulus, and the baseline characteristics of the cells such as their intrinsic proliferative capacity and state of differentiation which may be additional determinants of cellular responses to apoptotic stimuli. In addition, there may be compensatory changes in the HO-1-null cells that may have contributed to the observed effects.

In summary, we report that EA inhibits VSMC proliferation and migration and increases VSMC susceptibility to apoptosis and that these effects are independent of HO-1. Further studies should focus on defining the underlying molecular mechanisms and examining the functional significance of these observations in a suitable animal model. Although many intracellular signaling pathways may be affected by EA in VSMCs, a unifying hypothesis is that EA may promote a differentiated VSMC phenotype that is less prone to proliferation and migration and more prone to apoptosis. This hypothesis needs to be tested in future studies in order to identify potential novel molecular targets for intervention in vascular obstructive disorders.

\section{Acknowledgements}

We thank Dr. Stella Kourembanas, Dr. Mark Perrella, and Dr. S. Alex Mitsialis for their useful suggestions. This study was supported by a grant from the Peabody Foundation. This work contributed to the medical dissertation of Dr. Lineke Brenninkmeijer.

References

1 Agullo L, et al: Hypoxia and acidosis impair cGMP synthesis in microvascular coronary endothelial cells. Am J Physiol Heart Circ Physiol 2002;283:H917-H925.

2 D’Arcangelo D, et al: Acidosis inhibits endothelial cell apoptosis and function and induces basic fibroblast growth factor and vascular endothelial growth factor expression. Circ Res 2000;86:312-318.

- 3 D'Arcangelo D, Gaetano C, Capogrossi MC: Acidification prevents endothelial cell apoptosis by Axl activation. Circ Res 2002;91:e4e12. 
4 Nishimura Y, Romer LH, Lemasters JJ: Mitochondrial dysfunction and cytoskeletal disruption during chemical hypoxia to cultured rat hepatic sinusoidal endothelial cells: the $\mathrm{pH}$ paradox and cytoprotection by glucose, acidotic pH, and glycine. Hepatology 1998; 27:1039-1049.

$\checkmark 5$ Serrano CV Jr, et al: pH dependence of neutrophil-endothelial cell adhesion and adhesion molecule expression. Am J Physiol 1996; 271:C962-C970.

-6 Terminella C, Tollefson K, Kroczynski J, Pelli J, Cutaia M: Inhibition of apoptosis in pulmonary endothelial cells by altered $\mathrm{pH}$, mitochondrial function, and ATP supply. Am J Physiol Lung Cell Mol Physiol 2002;283: L1291-L1302.

$\checkmark 7$ Nishio K, et al: Effects of hypercapnia and hypocapnia on $\left[\mathrm{Ca}^{2+}\right]$ i mobilization in human pulmonary artery endothelial cells. J Appl Physiol 2001;90:2094-2100.

$\checkmark 8$ Cha SH, et al: Attenuation of extracellular acidic $\mathrm{pH}$-induced cyclooxygenase- 2 expression by nitric oxide. Mol Cells 2005;19:232238.

-9 Kumar S, Reusch HP, Ladilov Y: Acidic preconditioning suppresses apoptosis and increases expression of Bcl-xL in coronary endothelial cells under simulated ischaemia. J Cell Mol Med 2008;12:1584-1592.

10 Huck V, et al: Delay of acute intracellular pH recovery after acidosis decreases endothelial cell activation. J Cell Physiol 2007;211:399409.

-11 Christou H, Bailey N, Kluger MS, Mitsialis SA, Kourembanas S: Extracellular acidosis induces heme oxygenase-1 expression in vascular smooth muscle cells. Am J Physiol Heart Circ Physiol 2005;288:H2647-H2652.

12 Guan J, Wu X, Arons E, Christou H: The p38 mitogen-activated protein kinase pathway is involved in the regulation of heme oxygenase-1 by acidic extracellular $\mathrm{pH}$ in aortic smooth muscle cells. J Cell Biochem 2008; 105:1298-1306.
13 Morita T, Kourembanas S: Endothelial cell expression of vasoconstrictors and growth factors is regulated by smooth muscle cellderived carbon monoxide. J Clin Invest 1995; 96:2676-2682.

14 Morita T, Mitsialis SA, Koike H, Liu Y, Kourembanas S: Carbon monoxide controls the proliferation of hypoxic vascular smooth muscle cells. J Biol Chem 1997;272:3280432809.

15 Ollinger R, et al: Bilirubin: a natural inhibitor of vascular smooth muscle cell proliferation. Circulation 2005;112:1030-1039.

16 Liu XM, Chapman GB, Wang H, Durante W: Adenovirus-mediated heme oxygenase-1 gene expression stimulates apoptosis in vascular smooth muscle cells. Circulation 2002; 105:79-84.

17 Liu XM, Chapman GB, Peyton KJ, Schafer AI, Durante W: Carbon monoxide inhibits apoptosis in vascular smooth muscle cells. Cardiovasc Res 2002;55:396-405.

18 Yet SF, et al: Hypoxia induces severe right ventricular dilatation and infarction in heme oxygenase-1 null mice. J Clin Invest 1999; 103:R23-R29.

19 Duckers HJ, et al: Heme oxygenase-1 protects against vascular constriction and proliferation. Nat Med 2001;7:693-698.

20 Christou $\mathrm{H}$, et al: Prevention of hypoxia-in duced pulmonary hypertension by enhancement of endogenous heme oxygenase- 1 in the rat. Circ Res 2000;86:1224-1229.

-21 Connolly DT, Knight MB, Harakas NK, Wittwer AJ, Feder J: Determination of the number of endothelial cells in culture using an acid phosphatase assay. Anal Biochem 1986;152:136-140.

22 Wu X, Chang MS, Mitsialis SA, Kourembanas S: Hypoxia regulates bone morphogenetic protein signaling through C-terminalbinding protein 1. Circ Res 2006;99:240-247.
23 D’Arcangelo D, et al: Acidosis inhibits endothelial cell apoptosis and function and induces basic fibroblast growth factor and vascular endothelial growth factor expression. Circ Res 2000;86:312-318.

24 Austin C, Wray S: Interactions between $\mathrm{Ca}^{2+}$ and $\mathrm{H}^{+}$and functional consequences in vascular smooth muscle. Circ Res 2000;86:355363.

$>25$ Wang X, et al: Hypercapnic acidosis activates KATP channels in vascular smooth muscles. Circ Res 2003;92:1225-1232.

26 Santa N, et al: ATP-sensitive potassium channels mediate dilatation of basilar artery in response to intracellular acidification in vivo. Stroke 2003;34:1276-1280.

$>27$ Neylon CB: Potassium channels and vascular proliferation. Vascul Pharmacol 2002;38: 35-41.

28 Mandegar M, Yuan JX: Role of $\mathrm{K}^{+}$channels in pulmonary hypertension. Vascul Pharmacol 2002;38:25-33.

29 Morita T, Mitsialis SA, Koike H, Liu Y, Kourembanas S: Carbon monoxide controls the proliferation of hypoxic vascular smooth muscle cells. J Biol Chem 1997;272:3280432809.

30 Morita T, Kourembanas S: Endothelial cell expression of vasoconstrictors and growth factors is regulated by smooth muscle cellderived carbon mode. J Clin Invest 1995;96: 2676-2682.

-31 Brunt KR, et al: Protection of human vascular smooth muscle cells from $\mathrm{H}_{2} \mathrm{O}_{2}$-induced apoptosis through functional codependence between HO-1 and AKT. Arterioscler Thromb Vasc Biol 2006;26:2027-2034.

\$2 Abraham NG, et al: Heme oxygenase-1 attenuates glucose-mediated cell growth arrest and apoptosis in human microvessel endothelial cells. Circ Res 2003;93:507-514.

33 Kocanova S, et al: Induction of heme-oxygenase 1 requires the p38(MAPK) and PI3K pathways and suppresses apoptotic cell death following hypericin-mediated photodynamic therapy. Apoptosis 2007;12:731-741. 